\section{Military Technical College Kobry El-Kobbah, Cairo, Egypt.}

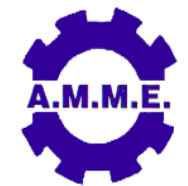

\title{
EFFECT OF CYCLIC PLASTIC DEFORMATION ON THE MECHANICAL PROPERTIES OF SPRING STEEL DIN $50 \mathrm{Cr} 3$
}

\author{
O. Elzahed ${ }^{1, *}$, M. Tolba Sallam ${ }^{1}$, K. Almazy ${ }^{1}$ and M. M. Osman ${ }^{1}$
}

\begin{abstract}
In this study the effect of cyclic plastic deformation on the mechanical properties of a light duty grade of spring steel DIN 50Cr3, commonly used in leaf spring was investigated. This steel has a chemical composition of $0.25 \% \mathrm{C}, 0.8 \% \mathrm{Cr}, 0.79 \% \mathrm{Mn}$, and $0.2 \%$ Si. Primarily, standard tensile specimens of this steel were cut and subjected to a quenching and tempering heat treatments. Austenitization was carried out at $870^{\circ} \mathrm{C}$ for $1 \mathrm{~h}$ followed by quenching in oil and then tempering was applied at $450^{\circ} \mathrm{C}$ for $1 \mathrm{~h}$. Subsequently, Different pre-plastic deformation strains of $1 \%, 2 \%$, and $2.5 \%$ were applied followed by various number of tensile stress cycles from zero to a maximum stress of $9 \%, 12.5 \%$, and $16.5 \%$ over the offset yield stress of the quenched and tempering specimens. These plastic strains and stress cycles can simulate the possible over loading of the vehicle. By increasing the number of cycles under a constant amplitude for a given fixed pre-plastic strains, the ultimate and offset yield strength of the spring material were sensibly increased while ductility was drastically decreased.
\end{abstract}

\section{KEYWORDS}

Spring steel, Austenitization, Quenching, Tempering, Offset yield.

1 Egyptian Armed Forces.

* Corresponding author; Email: osamaelzahed@mtc.edu.eg 


\section{INTRODUCTION}

Springs are flexible machine elements used for controlled application of force (or torque) or for storing and release of mechanical energy. Flexibility (elastic deformation) is enabled due to cleverly designed geometry or by using of flexible material. There are several types of springs such as spiral torsion spring, helical springs, torsion bars and... etc. Among this numerous types of spring leaf springs are considered an important candidate for heavy trucks and military vehicles suspensions most used materials are carbon steels, alloy steels, corrosion-resisting steels, phosphor bronze, spring brass and others [1]. The applications of spring steels in automotive industry require the ability of spring to absorb energy and withstand cyclic loads applied on it. So oil quenching is more convenient than water quenching, for spring steels, due to the effect of oil quenching on providing reasonable ductility and toughness with enough high strength [1, 2].

Oil quench and temper process offer enormous advantages to the light and heavy duty spring production because its treatment results can reveal optimum combination of toughness and ductility where high mechanical properties are the main design driver. Major requirements of the spring steel are high yield strength, high proportional limit, and high fatigue strength. These desirable properties of spring can be achieved firstly by a higher carbon content or with suitable alloying elements, and secondly by heat treatment [3]. Steel springs are used in hard, high strength condition. To attain these properties springs are hardened and tempered. Small springs can be formed in the prehardened state, while larger springs are formed in the annealed state then hardening is carried out after fabrication [4].

Mechanical properties of most materials not only depend on the variation of metallurgical factors, such as grain size, alloying element, quenching, aging, and annealing, but also are intensively influenced by service conditions including the loading history [5]. During service, structural components can either be subjected to stress that remains in the elastic range or exceeds the elastic limit. These components such as springs subjected to cyclic loading that may be in plastic strain region due to unintentionally overloading or road effects. As a result, the design of these components requires a special attention for the assessment of stress and strain fields in the critical domains. Components when subjected to relatively high stress above the elastic limit may fail at low numbers of plastic loading cycles, because of cracks usually nucleate from plastic straining in localized areas.

\section{EXPERIMENTAL PROCEDURES}

\section{Material Used}

The material used in this study is DIN $50 \mathrm{Cr} 3$ spring steel with chemical composition, determined by two different techniques using X-Ray florescence and spark emission spectroscopy, shown in Table 1. This material was received in the form of stripes having a width of $60 \mathrm{~mm}$ and a thickness of $6 \mathrm{~mm}$, in the annealed state.

\section{Specimen Preparation}

Standard specimens were prepared with the required dimensions for tensile 
Table 1. Chemical composition of the DIN $50 \mathrm{Cr} 3$ spring steel.

\begin{tabular}{|c|c|c|c|c|}
\hline $\mathrm{Fe}$ & $\mathrm{C}$ & $\mathrm{Si}$ & $\mathrm{Mn}$ & $\mathrm{Cr}$ \\
\hline $97.961 \%$ & $0.251 \%$ & $0.2 \%$ & $0.788 \%$ & $0.8 \%$ \\
\hline
\end{tabular}

measurements. The shape and dimensions of these standard specimens were chosen according to ASTM E8 standard [6], and illustrated in Fig. 1. These tensile standard specimens were precisely machined to the indicated dimensions using a laser cutting machine type "Trulaser 3030", shown in Fig. 2.

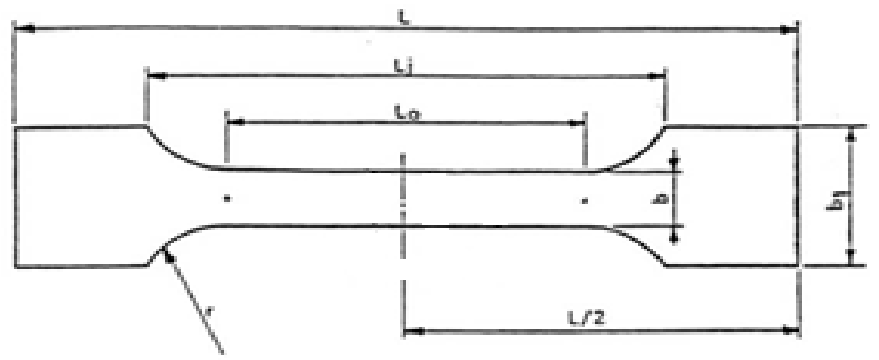

\begin{tabular}{|c|c|c|c|c|c|c|}
\hline $\mathrm{L}$ & $\mathrm{L}_{\mathrm{i}}$ & $\mathrm{L}_{\circ}$ & Thickness $(\mathrm{t})$ & $\mathrm{r}$ & $\mathrm{b}$ & $\mathrm{b}_{1}$ \\
\hline $120 \mathrm{~mm}$ & $100 \mathrm{~mm}$ & $45 \mathrm{~mm}$ & $6 \mathrm{~mm}$ & $76 \mathrm{~mm}$ & $7.5 \mathrm{~mm}$ & $10 \mathrm{~mm}$ \\
\hline
\end{tabular}

Fig.1. Shape and dimensions of the used tensile test specimen.
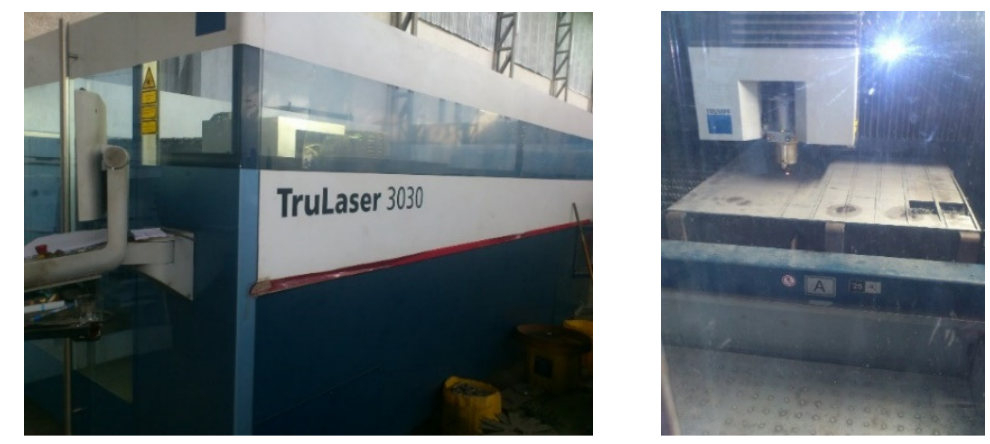

Fig. 2. Laser cutting machine type (Trulaser 3030).

\section{Heat Treatment Procedure}

During all heat treatment cycles applied on the standard manufactured specimens heating was carried out in open air electric furnace with max temperature $1100^{\circ} \mathrm{C}$. Firstly the specimens are heated to a proper austenitization temperature of $870^{\circ} \mathrm{C}$ for $1 \mathrm{~h}$ to insure homogenous full austenitic structure. The specimens were then quenched in oil, at a rate faster than its critical cooling rate, to attain martensitic phase. The final step of this heat treatment cycle is tempering. Tempering is the process of heating the hardened steel to a temperature lower than the critical temperature $\left(A_{1}\right)$. After soaking at that temperature, specimens are cooled in air to 
room temperature. Tempering process is occurred to obtain high strength with sufficient ductility. In this study tempering takes place at temperature $250^{\circ} \mathrm{C}$ for $1 \mathrm{~h}$.

\section{Mechanical Evaluation}

The heat treated specimens were further subjected to mechanical evaluation by Appling standard tensile test. The tensile test was carried out using electromechanical tensile testing machine type (GALDABINI Quasar 100) with maximum loading capacity $100 \mathrm{kN}$. Tensile specimens were loaded by a quasi-static strain rate of $10^{-3} \mathrm{~s}^{-1}$.

\section{RESULTS AND DISCUSSION}

\section{Evaluation of Mechanical Properties after the Recommended Heat Treatments}

For spring steels, in order to provide the essential requirements needed for their applications in the various domains, they have to possess high hardness and strength with reasonable ductility and toughness [7]. Moreover, they should provide enough high elastic range, which can be obtained by the achievement of the highest possible ratio between their offset yield strength and ultimate strength $\left(\sigma_{0.2} / \sigma u\right)[8$, 9]. For DIN $50 \mathrm{Cr} 3$ spring steel, heating to an austenitization temperature of $870^{\circ} \mathrm{C}$ followed by quenching in oil and then tempering at $450^{\circ} \mathrm{C}$ for $1 \mathrm{~h}$, can satisfy these requirements. As a result, these quenching and tempering parameters were selected to be the optimum recommended conditions based on a previous study in this domain [2].The stress strain curve of the heat treated specimens under the mentioned conditions is illustrated in Fig.3, where the values of the ultimate tensile strength, offset yield strength, and ductility were $1500 \mathrm{MPa}, 1330 \mathrm{MPa}$ and $9 \%$ respectively. These mechanical values were taken to be a reference to study and evaluate the effect of applying several cyclic plastic loading on the evolution of mechanical properties of this steel.

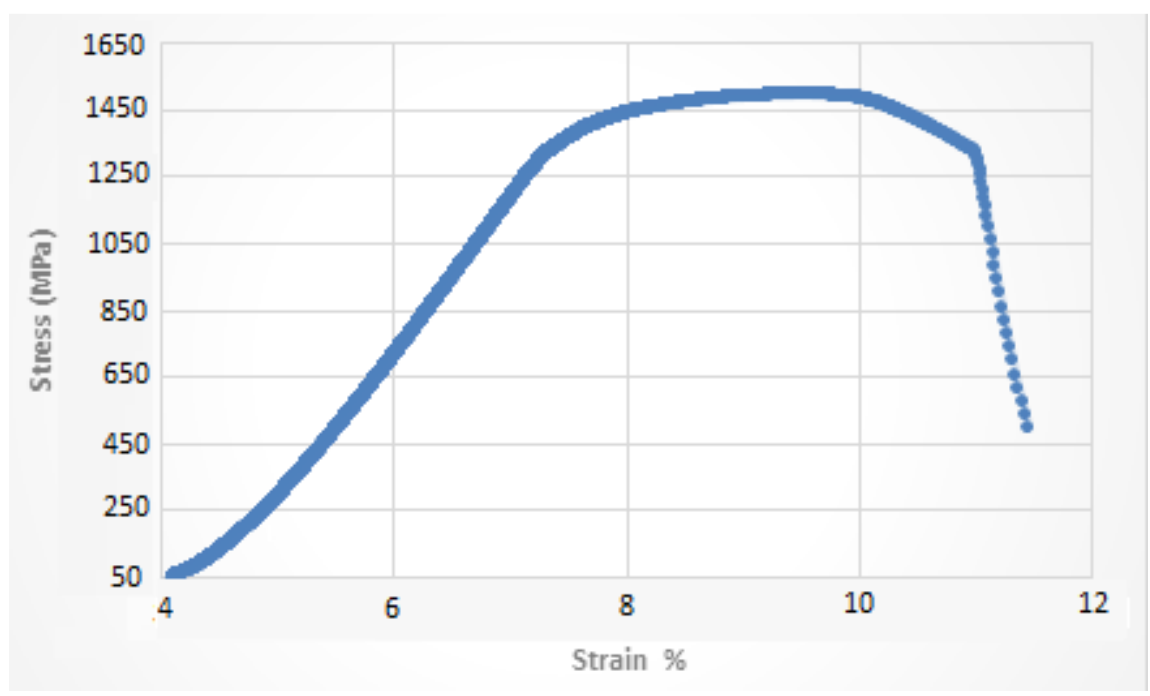

Fig. 3. Stress Strain curve obtained on standard tensile test specimens of DIN $50 \mathrm{Cr} 3$ spring steel, heated to $870^{\circ} \mathrm{C}$ then quenched in oil followed by tempering at $450^{\circ} \mathrm{C}$ for one hour. 


\section{Effect of Applying Repeated Plastic Loading Cycles after a Constant Pre-Plastic Strain}

In the normal ideal conditions, the loading regime of the spring material for the assigned applications should be in the elastic range below the offset yield strength [9]. In the real actual conditions, sometimes the spring is unintentionally overloaded and stressed beyond this elastic limit to the plastic range for limited number of cycles during service $[10,11]$. The following stress regimes can simulate the probable excessive loading conditions after the mentioned heat treatments.

\section{a- Effect of applying an Initial plastic strain of $1 \%$ followed by different number of plastic loading cycles of a maximum stress of $9 \%$ above the initial offset yield strength:}

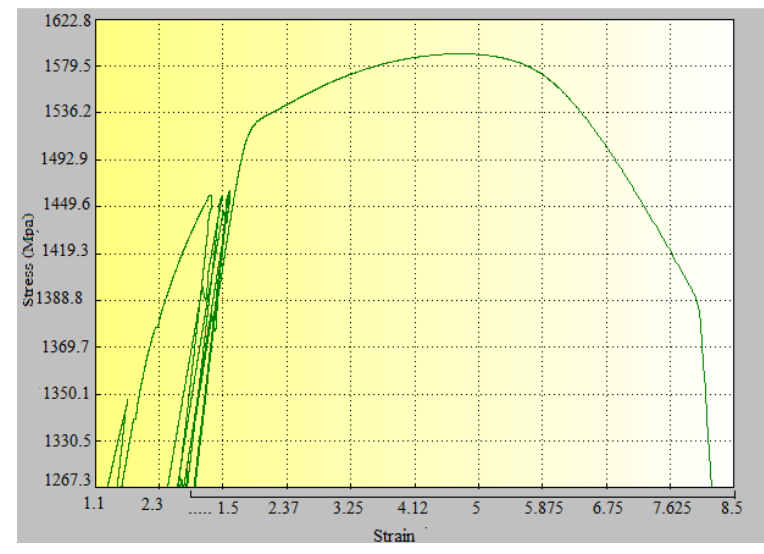

(a)

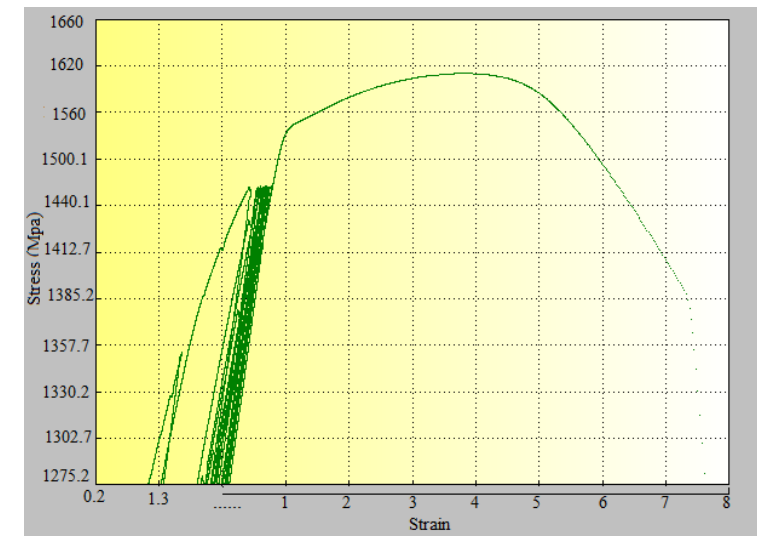

(b)

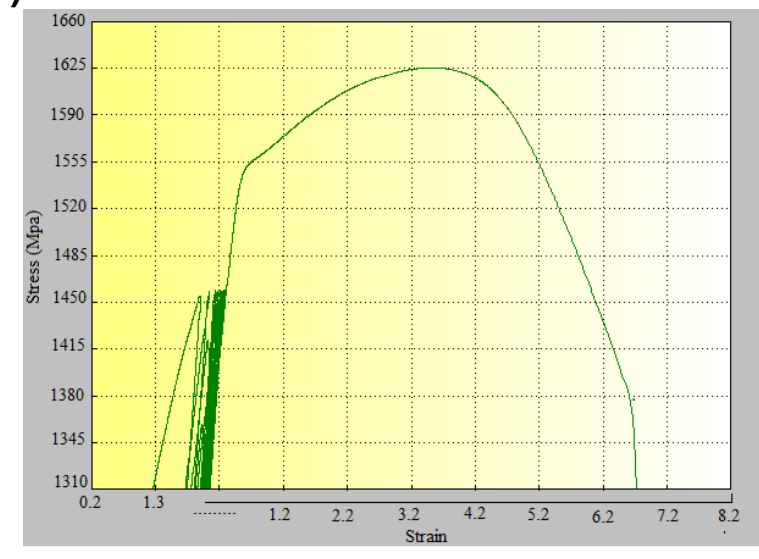

(c)

Fig.4. Stress strain diagrams of specimens subjected to an initial plastic strain of $1 \%$ followed by the application of different number of plastic strain cycles of a maximum stress of $9 \%$ above the initial offset yield strength. a) 5 cycles. b) 10 cycles. c) 15 cycles.

Figure 4 shows stress strain diagrams after the application of an Initial plastic strain of $1 \%$ followed by different number of repeated plastic loading cycles of a maximum stress of $9 \%$ above the initial offset yield strength on the spring steel DIN 50Cr3 subjected to the indicated recommended heat treatments by quenching and tempering. After the application of five plastic loading cycles the values of the 
ultimate tensile strength and offset yield strength were increased by $6 \%, 12.5 \%$, respectively, while the ductility was decreased by $16.7 \%$. When the number of loading cycles was increased to ten, the values of the ultimate tensile strength and offset yield strength were increased by $7.3 \%, 15.8 \%$, in the same order, and the ductility was decreased by $22.3 \%$. Finally, increasing the number of loading cycles to fifteen, the values of the ultimate tensile strength and offset yield strength were increased by $8.3 \%, 16.5 \%$, respectively, and the ductility was decreased by $30 \%$. This can indicate that, from one hand, the strength was substantially increased with the increase of the number of loading cycles, and from the other hand, more sensible increase of the offset yield strength was visualized relative to that observed for ultimate tensile strength. Moreover the ductility was seriously decreased and leading to an embrittlement behavior of the material that may cause pre-mature fracture for any further over loading.

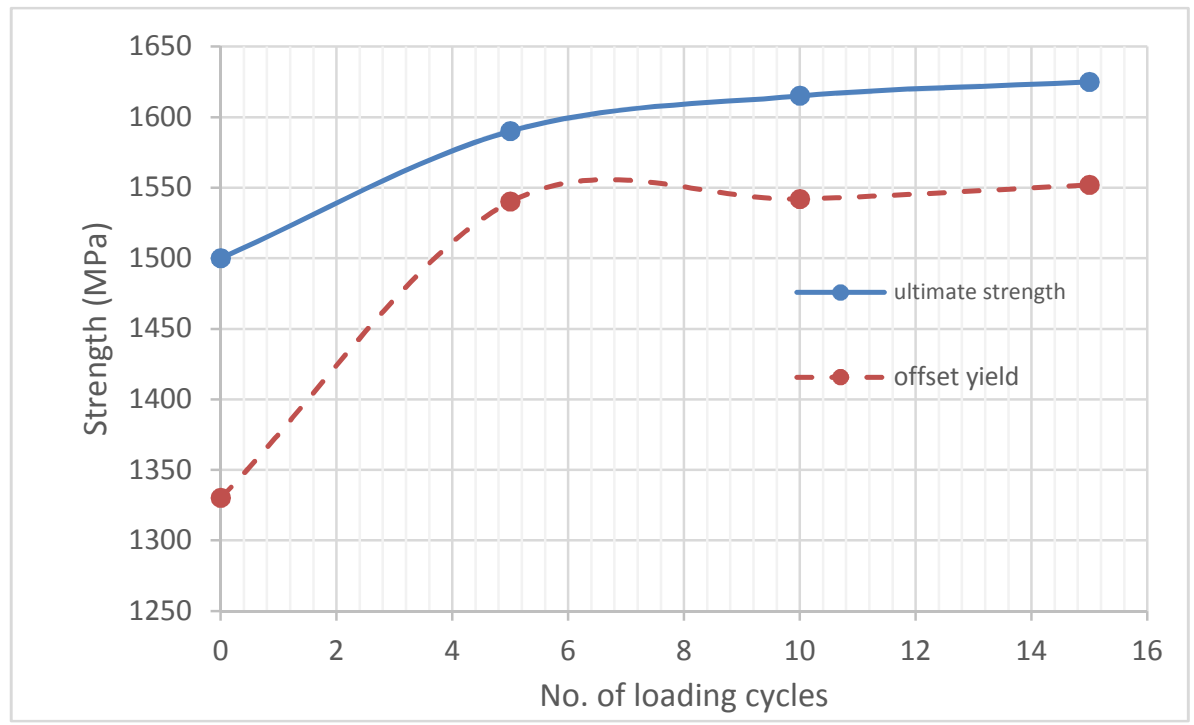

Fig. 5. The effect of the number of loading cycles, after an initial plastic strain of $1 \%$, on the ultimate tensile strength and offset yield strength of the spring steel DIN $50 \mathrm{Cr} 3$.

The effect of the number of loading cycles after an initial plastic strain of $1 \%$ on the ultimate tensile strength and offset yield strength of the spring steel DIN $50 \mathrm{Cr} 3$ is illustrated in Fig.5. We can clearly state that after the application of five loading plastic cycles the values of ultimate tensile strength and offset yield strength were increased to1590 $\mathrm{MPa}$ and $1540 \mathrm{MPa}$ respectively. When the number of cycles attains fifteen, both values of strength were increased to $1625 \mathrm{MPa}$ and $1552 \mathrm{MPa}$. This indicates that both ultimate and offset yield strength considerably increased, even after the application of limited number of plastic loading cycles. Further increase of this loading cycle has relatively slight increase of the values of strength.

Figure 6 shows the effect of the number of loading cycles after an initial plastic strain of $1 \%$ on the ductility of the spring steel DIN $50 \mathrm{Cr}$. for five loading plastic cycles the value of the ductility was decreased to $7.625 \%$. When the number of cycles reaches fifteen, this value of ductility was further decreased to $6.3 \%$. This indicates that ductility was gradually decreased by increasing the number of plastic loading cycles. This drop after the application of 15 plastic loading cycles attains $30 \%$. 


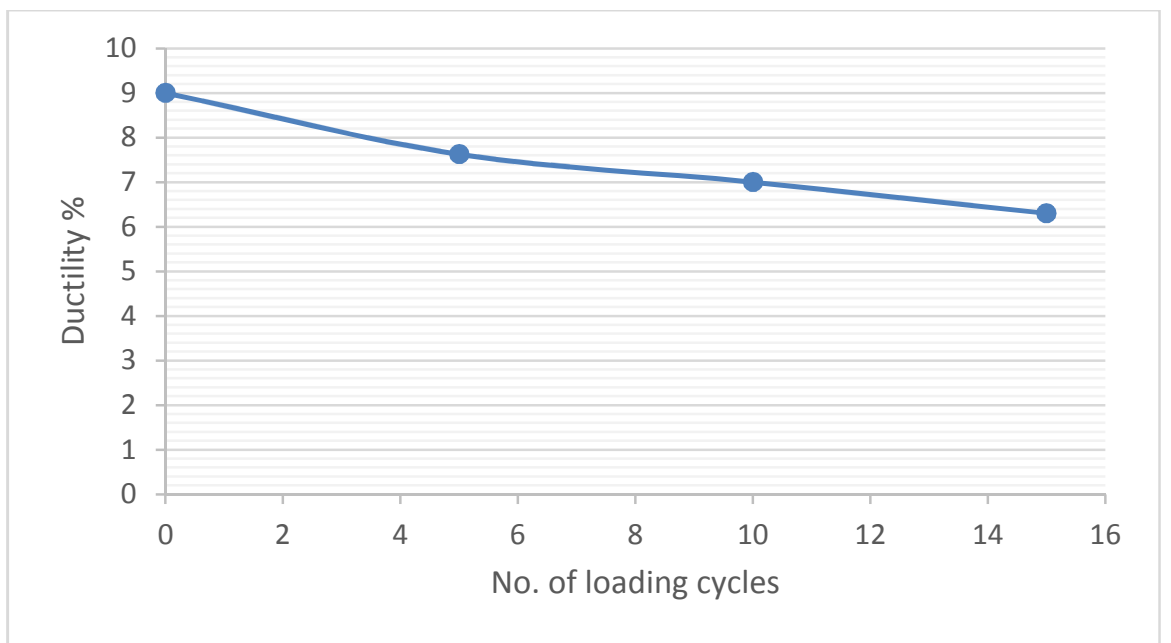

Fig. 6. The effect of the number of loading cycles, after an initial plastic strain of $1 \%$, on the ductility the spring steel DIN 50Cr3.

b- Effect of applying an Initial plastic strain of $2 \%$ followed by different number of plastic loading cycles of a maximum stress of $12.5 \%$ above the initial offset yield strength:

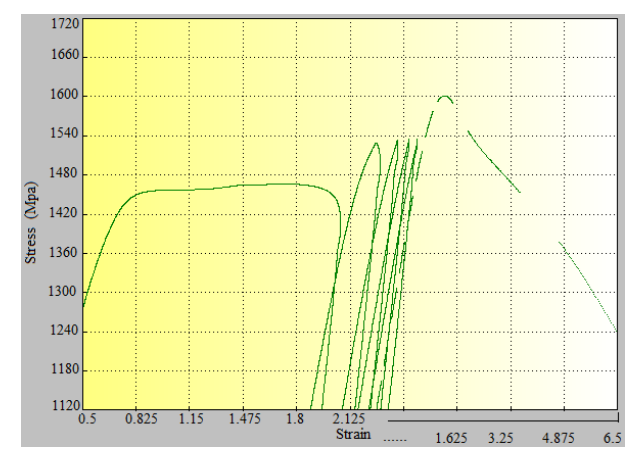

(a)

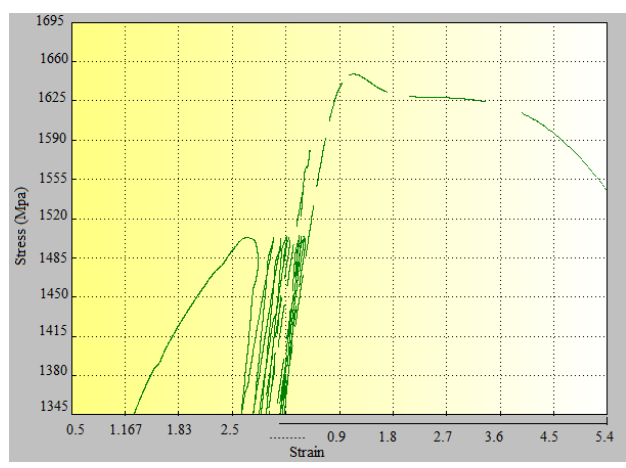

(b)

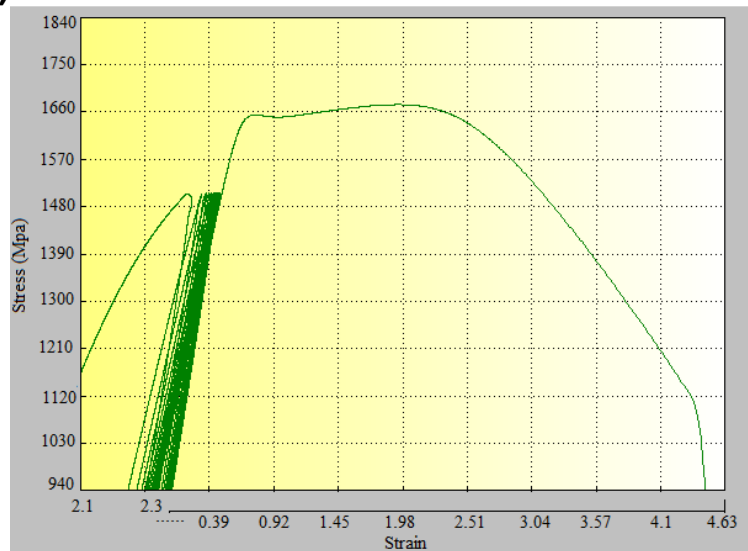

(c)

Fig. 7. Stress strain diagrams of specimens subjected to an initial plastic strain of $2 \%$ followed by the application of different number of plastic strain cycles of a maximum stress of $12.5 \%$ above the initial offset yield strength. a) 5 cycles. b) 10 cycles. c) 15 cycles. 
Figure 7 illustrates the stress strain diagrams obtained after an Initial plastic strain of $2 \%$ followed by various numbers of repeated plastic loading cycles of a maximum value of $12.5 \%$ over the initial offset yield strength of the spring steel DIN 50Cr3 subjected to the indicated recommended heat treatment by quenching and tempering. The stress strain diagram obtained after five plastic loading cycles provides percentages increase of ultimate tensile strength and offset yield strength of $6.6 \%$ and $15.7 \%$, respectively, while ductility was decreased by $33.3 \%$. For ten plastic loading cycles the values of the ultimate tensile strength and offset yield strength were increased by $10 \%, 18 \%$, respectively and the ductility was decreased by $48.8 \%$. When applying 15 plastic loading cycles the values of the ultimate tensile strength and offset yield strength were increased, in same manner, by $11.33 \%, 24 \%$, respectively and the ductility was decreased by $53.3 \%$.

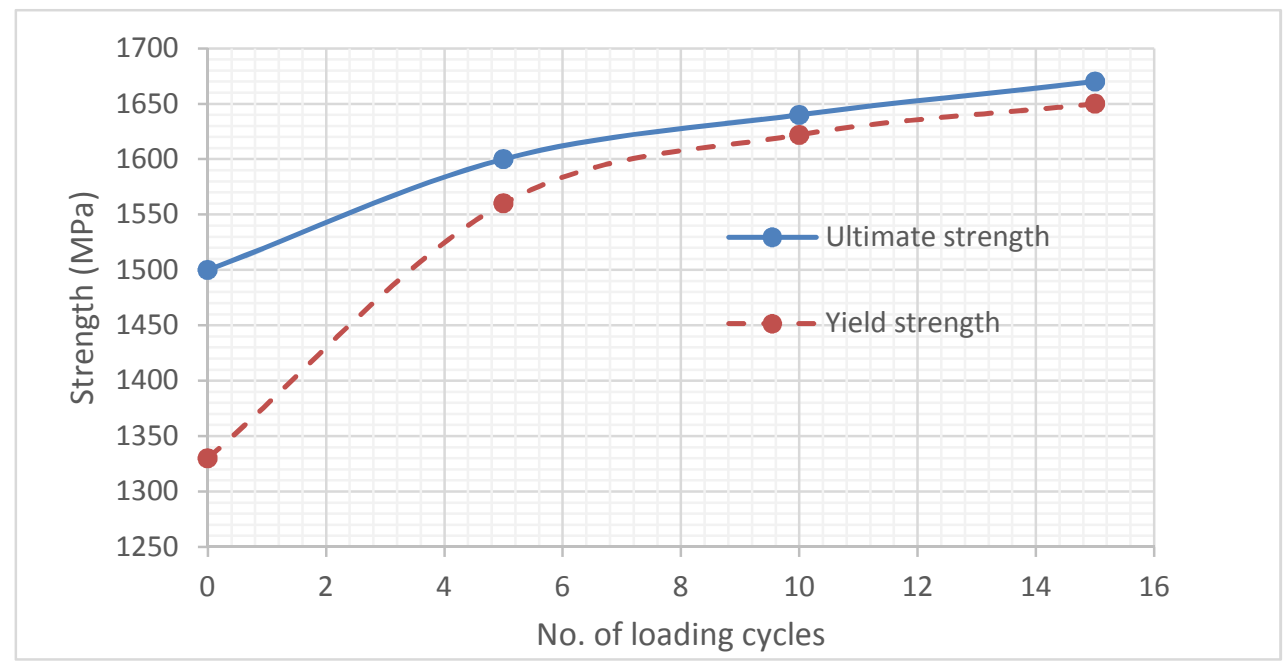

Fig. 8. The effect of the number of loading cycles, after an initial plastic strain of $2 \%$, on the ultimate tensile strength and offset yield strength of the spring steel DIN 50Cr3.

The effect of the number of loading cycles after an initial plastic strain of $2 \%$ on the ultimate tensile strength and offset yield strength of the spring steel DIN $50 \mathrm{Cr} 3$ is illustrated in Fig.8. After the application of five loading plastic cycles the values of ultimate tensile strength and offset yield strength were increased to $1600 \mathrm{MPa}$ and $1540 \mathrm{MPa}$ respectively. When the number of cycles attains fifteen, both values of strength were increased to $1670 \mathrm{MPa}$ and $1650 \mathrm{MPa}$. This indicates that the major increase of ultimate and offset yield strength occurs after the early plastic loading cycles (up to 5 cycles). Further increase of the number of loading cycles leads to moderate rise of these values of strength.

The effect of the number of loading cycles after an initial plastic strain of $2 \%$ on the ductility of the spring steel DIN 50Cr3 was shown in Fig. 9. Similar to was observed in the previous case, the ductility gradually decreases with increasing the number of plastic loading cycles, and attains a value of 4.2 after fifteen plastic loading cycles. This drop represents about $53.3 \%$ of the initial value provided by this spring steel without plastic loading. 


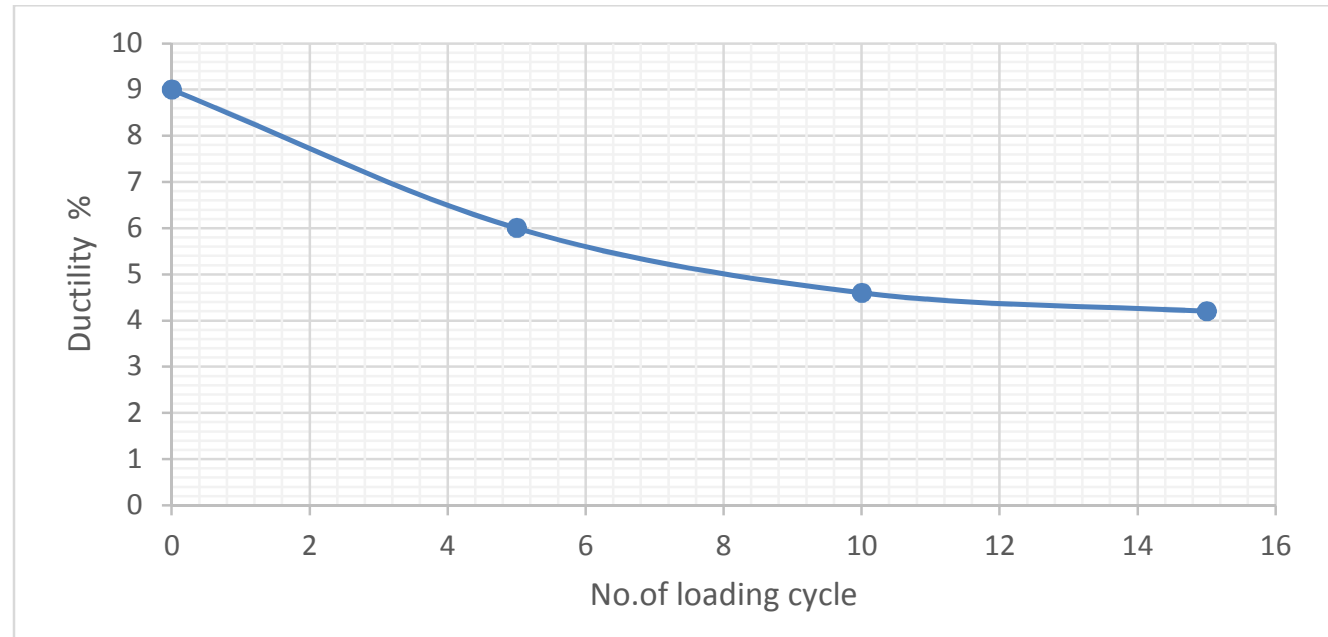

Fig. 9. The effect of the number of loading cycles, after an initial plastic strain of $2 \%$, on the ductility the spring steel DIN 50Cr3.

c- Effect of applying an Initial plastic strain of $2.5 \%$ followed by different number of plastic loading cycles of a maximum stress of $16.5 \%$ above the initial offset yield strength:

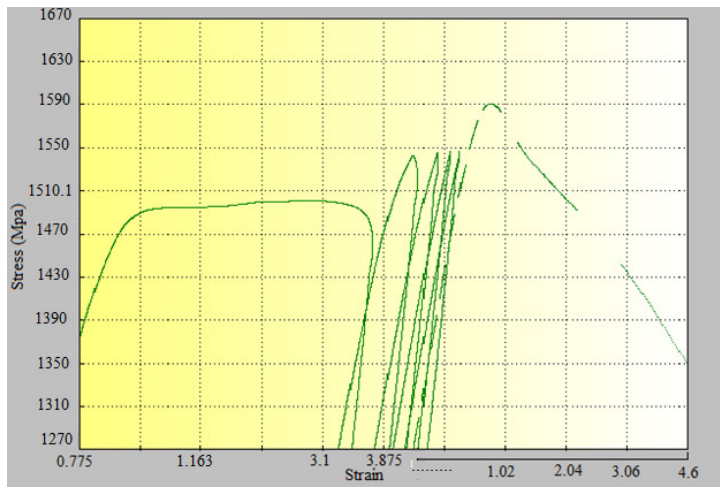

(a)

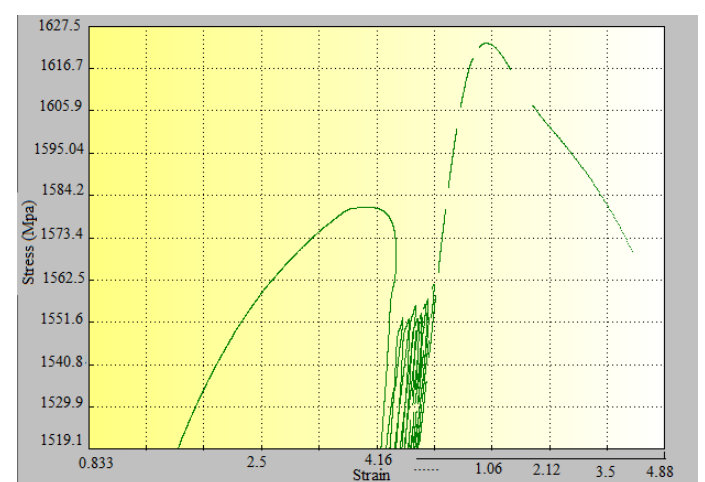

(b)

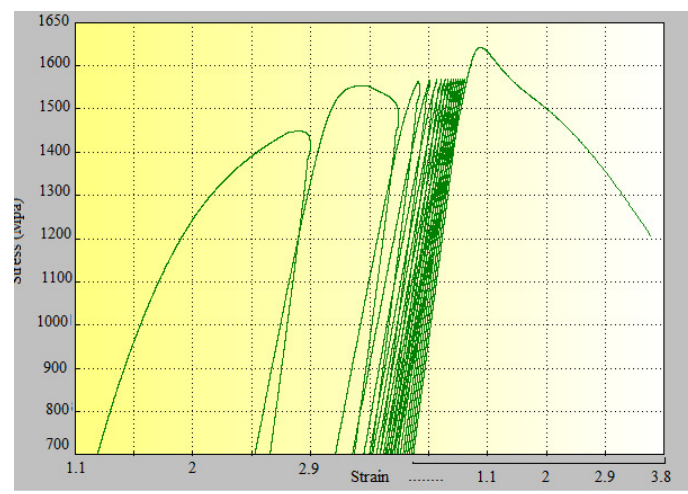

(c)

Fig. 10. Stress strain diagrams of specimens subjected to an initial plastic strain of $2.5 \%$ followed by the application of different number of plastic strain cycles of a maximum stress of $16.5 \%$ above the initial offset yield strength. a) 5 cycles. b) 10 cycles. c) 15 cycles. 
Stress strain diagrams after an initial plastic strain $2.5 \%$ followed by different number of plastic strain cycles of a maximum value of $16.5 \%$ over the initial offset yield strength of the spring steel DIN 50Cr3 subjected to the specified recommended heat treatments, by quenching and tempering, were shown in Fig.10. We can also clearly indicate that, similar to the previous cases, after the application of five plastic loading cycles an increase of the values of the ultimate tensile strength and offset yield strength, by $6 \%, 13.5 \%$ can be recorded. On the contrarily the ductility was seriously decreased by $55.5 \%$. For ten plastic strain loading cycles the values of the ultimate tensile strength and offset yield strength were increased by $8 \%, 18.8 \%$, respectively and the ductility was decreased by $61 \%$. Finally for 15 plastic loading cycles the values of the ultimate tensile strength and offset yield strength were increased by 8.3 $\%, 19.5 \%$, respectively and the ductility was dramatically decreased by $67.6 \%$.

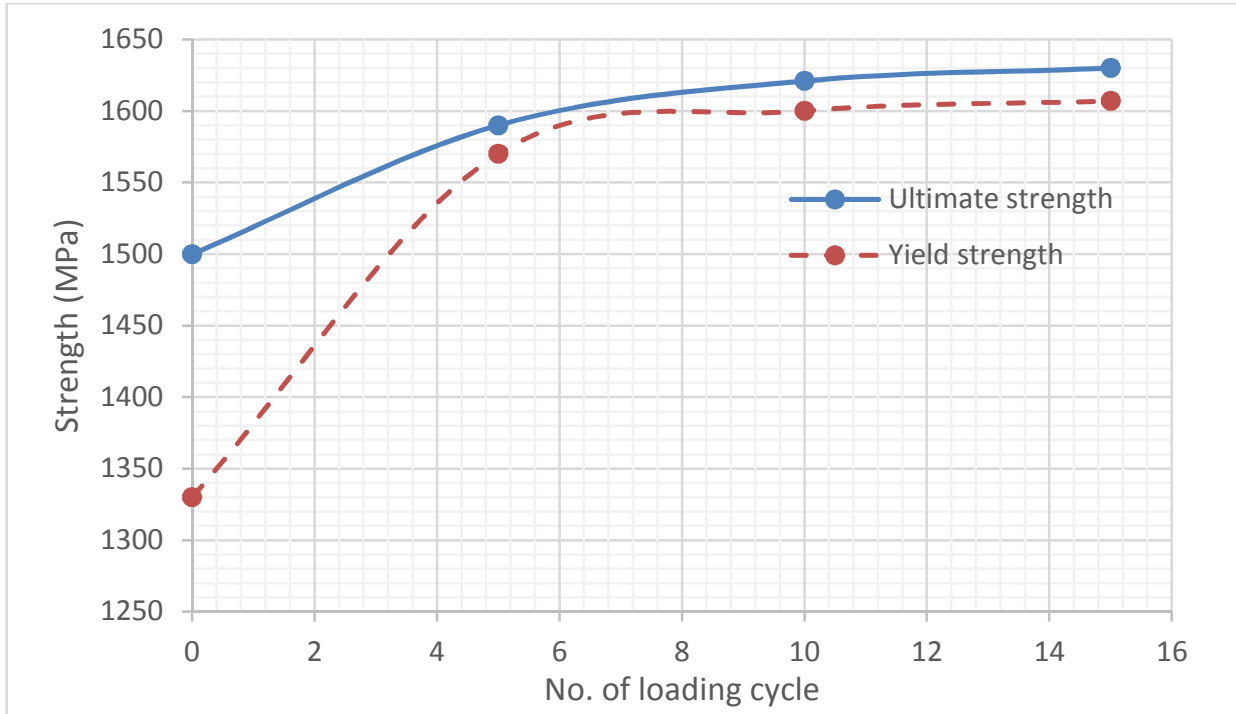

Fig. 11. The effect of the number of loading cycles, after an initial plastic strain of $2.5 \%$, on the ultimate and offset yield strength of the spring steel DIN 50Cr3

Figure 11 shows the effect of the number of loading cycles after an initial plastic strain of $2.5 \%$ on the ultimate tensile strength and offset yield strength of the spring steel DIN 50Cr3. After the application of only five plastic loading cycles the values of ultimate tensile strength and offset yield strength were increased to $1590 \mathrm{MPa}$ and $1570 \mathrm{MPa}$ respectively. When the number of loading cycles was augmented to fifteen, both values of strength were slightly raised to $1630 \mathrm{MPa}$ and $1600 \mathrm{MPa}$. This confirms that the values of spring steel mechanical strength is significantly increased, even after the application of limited number of plastic loading cycles. Further increase in these cycles leads to additional slight rise in the strength of this steel.

Figure 12 illustrates the effect of the number of loading cycles after an initial plastic strain of $2.5 \%$ on the ductility of the spring steel DIN $50 \mathrm{Cr} 3$ subjected to the referred heat treatments. In case of applying only five plastic loading cycles the value of the ductility was substantially decreased to $4 \%$. In the same manner by increasing the number of cycles to fifteen, this value of ductility was further decreased to $2.9 \%$. This also confirms that, in the first stage, ductility is significantly decreased by the application of only limited number of plastic loading cycles, while in the second stage 


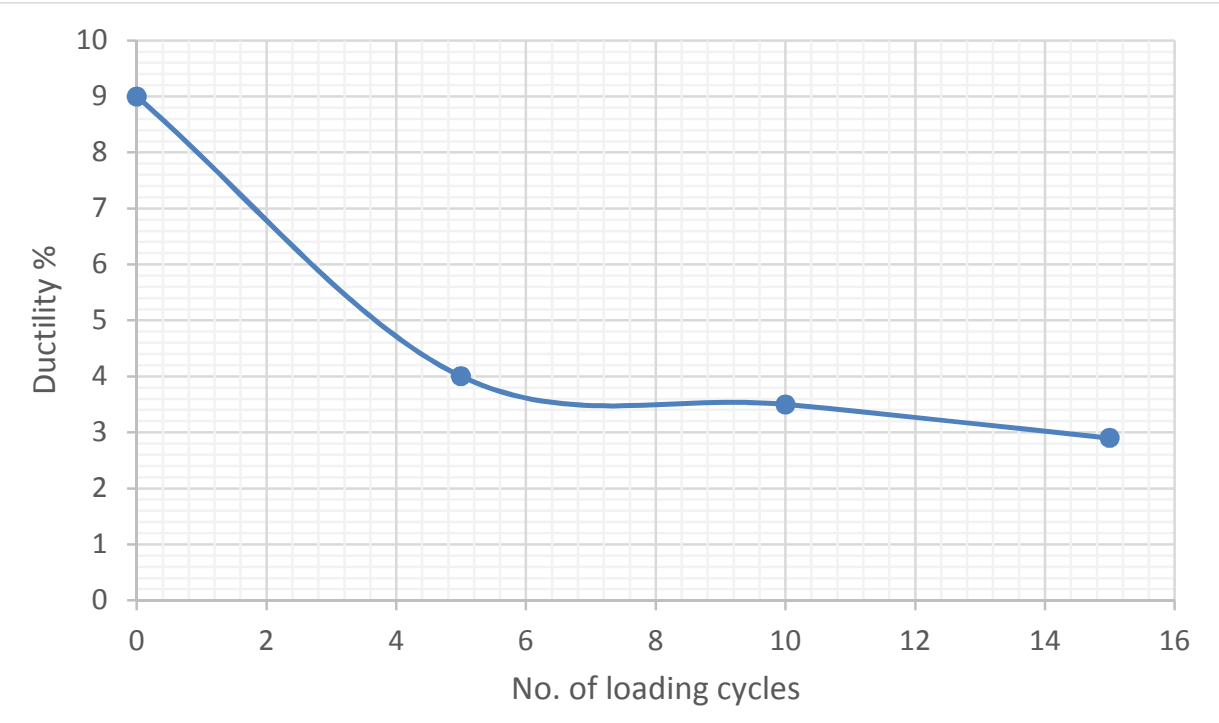

Fig.12. The effect of the number of loading cycles, after an initial plastic strain of $2.5 \%$, on the ductility the spring steel DIN $50 \mathrm{Cr} 3$.

ductility continues to slightly decrease by the application of further more loading cycles that simulate the improper over loading of this spring steel.

In the initial state of this spring steel, after the implemented manufacturing procedure and the prescribed heat treatments by quenching and tempering, the dislocation substructure exhibit a relatively high value of dislocation density imparting the required hardening level and the assigned mechanical properties. When the spring material is subjected to further plastic deformation, during service and operation for the allocated applications, the pinning and multiplication of dislocations as well as the mutual intersections among them will be sensibly enlarged, and leads to the formation of additional dislocations. Moreover, their interactions with grain and twin boundaries increases the resistance to plastic deformation and promoting a brittle behavior of the material, and the depletion of its inherent ductility $[15,16]$. Consequently, with further repeated plastic straining, the initiation and propagation of micro cracks may lead to pre-mature fracture of the spring material,

Figure 13 illustrates the fracture surface of the tensile test specimens after the application of $1 \%$ plastic strain followed by 5 loading cycles of maximum value of $9 \%$ above the initial offset yield. We can clearly state that this fracture exhibits a dominant ductile trans-granular dimple fracture modes, with limited brittle intergranular fracture cracks. When the material is subjected to more sever plastic strain and higher number of plastic straining cycles, as shown in Fig.14 which presents the fracture surface of the tensile test specimens after the application of $2.5 \%$ plastic strain followed by 15 loading cycles of a maximum value of $12.5 \%$ above the initial offset yield, the brittle inter-granular fracture modes and cracks become the dominant modes of fracture while ductile trans-granular dimple fracture modes were noticeably diminished. This confirms the application of service plastic deformation and plastic loading cycles can have a deep influence on the transformation of the spring material to the brittle behavior and the occurrence of early fractures. 


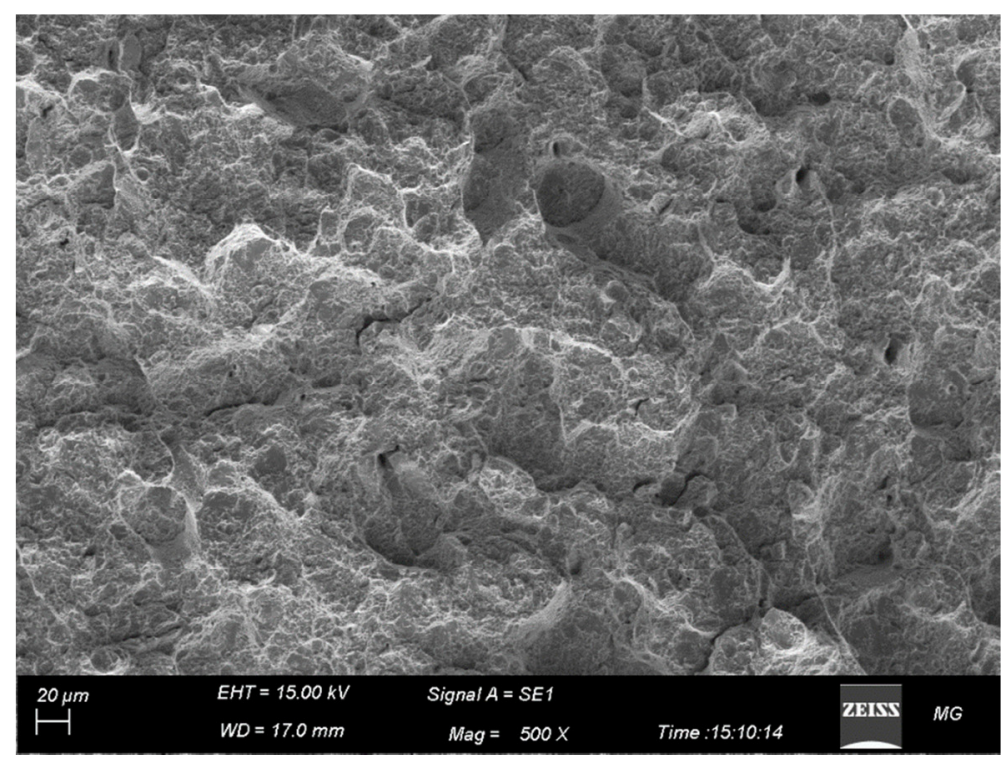

Fig.13. Fracture surface of the tensile test specimens after the application of $1 \%$ plastic strain followed by 5 loading cycles of maximum value of $9 \%$ above the initial offset yield.

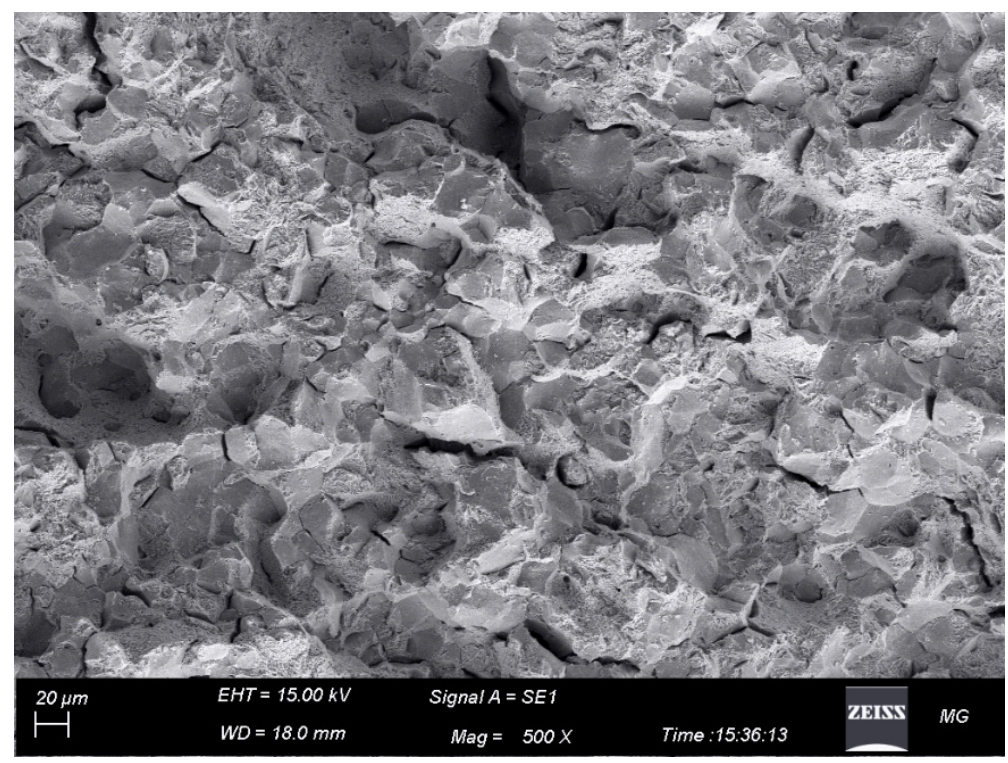

Fig.14. fracture surface of the tensile test specimens after the application of $2.5 \%$ plastic strain followed by 15 loading cycles of a maximum value of $12.5 \%$ above the initial offset yield.

\section{CONCLUSIONS}

The following conclusions have been drawn from the experimental result and discussion:

- For spring steels, by increasing the value of the initial pre-plastic strain and the number of plastic loading cycles, that simulate the over loading by the exposer of this material to loading conditions beyond the elastic range, during the application, the values of both ultimate and offset yield strength are increased. 
- More sensible increase of the offset yield strength was visualized relative to that observed for ultimate tensile strength, for all plastic loading conditions. It attains, for offset yield strength, about double the percentage of increase for ultimate strength.

- The ductility of the spring steel was decreased drastically by increasing the number of plastic loading cycles and the value of the initial pre-plastic strain. This drop may reach more than $50 \%$ of the initial ductility, moreover its majority takes place during the early plastic loading cycles.

- The fracture of the spring steels demonstrates more brittle fracture modes, by inter-granular separations, after the application of successive plastic loading cycles. This can lead to pre- mature failures of this steel.

\section{REFERENCES}

[1] G. E Dieter, Mechanical Metallurgy. Cambridge: McGraw-Hill Book, 1998.

[2] O. Elzahed, M. T. Sallam, K. Almazy, M. M. Osman, "the effect of different heat treatment regimes on the mechanical and microstructure characteristics of $\mathrm{Si}-\mathrm{Cr}$ spring steel", ASAT, MTC, Cairo, Egypt, 2017.

[3] A. Nagesha, M. Valsan, R. Kannan, K. B. Sankara and S. L. Mannan, "Influence of temperature on the low cycle fatigue behavior of a modified $9 \mathrm{Cr}-1$ Mo ferritic steel", Int. J. of Fatigue, 2002.

[4] R. W. Landgraf, J. Morrow, and T. Endo, "Determination of the cyclic stressstrain curve", JMLSA; 4(1):176, 1969.

[5] D. T. Raske and J. M. Morrow. "Mechanics of materials in low cycle fatigue testing. In: Manual on low cycle fatigue testing" Philadelphia (PA), ASTM STP 465. p.1, 1969.

[6] Y. Duyi, X. Yuandong, L. Xiao and H. Cha, "Effects of low-cycle fatigue on static mechanical properties, microstructures and fracture behavior of 304 stainless steel" J. Mat. Sci.and Eng., A527, 4092-4102, 2010.

[7] H. E. Boyer, "Atlas of Stress-Strain Curves", ASM International, Metal Park, Ohio, 1987.

[8] S. Wole, "Mechanical Properties of Engineered Materials", Marcel Dekker Inc., 2003.

[9] H. J. Bassler and D. Eifler, "Low Cycle Fatigue and Elasto-Plastic Behavior of Materials", Elsev. Sci. Ltd, 285, 1998.

[10] R. G. Teteruk, H. J. Maier and H. J. Christ, "Low Cycle Fatigue and ElastoPlastic Behavior of Materials", Elsev.Sci, Ltd. 321, 1998.

[11] M. Klesnil and P. Lukás, "Fatigue of Metallic Materials", Elsev. New York, 1980.

[12] B. I. Sandor, "Fundamentals of Cyclic Stainless and Strain", University of Wisconsin Press, Ltd., 1972.

[13] P. G. Forrest, "Fatigue of Metals", Pergamon Press, London, 1962.

[14] P. Larour and P. Verleysen, "Influence of uniaxial, biaxial and plane strain prestraining on the dynamic tensile properties of high strength sheet steels", Eighth international, 2006.

[15] T. Davidson, "Microstructure of Steels and Cast Irons". Springer, Berlin Heidelberg. 2004.

[16] R. W. Cahn, "Physical metallurgy". Amsterdam: Elsev. Sci., B.V. 1996. 